\title{
Longwall Mining Stability in Take-Off Phase
}

\author{
María-Belén Prendes-Gero, ${ }^{1}$ José Alcalde-Gonzalo, ${ }^{2}$ Pedro Ramírez-Oyanguren, ${ }^{3}$ \\ Francisco-José Suárez-Domínguez, ${ }^{1}$ and Martina-Inmaculada Álvarez-Fernández ${ }^{4}$ \\ ${ }^{1}$ Department of Construction and Manufacture Engineering, Polytechnic School of Mieres, University of Oviedo, Mieres, \\ 33600 Asturias, Spain \\ ${ }^{2}$ Department of Exploitation and Prospecting Mines, Mining Engineering School, University of Oviedo, Oviedo, 33004 Asturias, Spain \\ ${ }^{3}$ Department of Exploitation Mines, Polytechnic University of Madrid, 28040 Madrid, Spain \\ ${ }^{4}$ Department of Exploitation and Prospecting Mines, Mining Engineering School, University of Oviedo, Oviedo, 33004 Asturias, Spain
}

Correspondence should be addressed to María-Belén Prendes-Gero; belen@git.uniovi.es

Received 6 June 2013; Accepted 23 July 2013

Academic Editor: Ga Zhang

Copyright (C) 2013 María-Belén Prendes-Gero et al. This is an open access article distributed under the Creative Commons Attribution License, which permits unrestricted use, distribution, and reproduction in any medium, provided the original work is properly cited.

\begin{abstract}
Mechanised longwall mining is one of the more commonly employed exploitation methods in underground mines in the north of Spain as well as in the rest of the world. It is continuously changing and evolving, with new techniques, technology, equipment, and face management practices and systems appearing for the purposes of improving aspects such as operational and financial performances and, above all, the safety of the miners. Despite its importance, there are no regulations for the mining of longwall coal seams. This work aims to contribute to an advance in the design and optimisation of the roof support in longwall mining, analysing the stability of the roof using a method based on the resistance of materials, which considers the characteristics of the properties of the roof materials. The influence of not only the individual elements of support but also the coalface, which is considered one more supporting element, is investigated. The longitudinal and transverse spacings of the support and the number of walkways constituting the exploitation panel are analysed. The proposed formulation is validated by information gathered in a mine located in the region of Castilla-Leon.
\end{abstract}

\section{Introduction}

Important reserves of coal exist in Spain, which can contribute to reducing the energetic dependence on other countries [1]. Though their importance has diminished gradually, the National Plan of Strategic Reservation of Coal 2006-2012 and the New Model of Integral and Sustainable Development of the Mining Regions [2] established a minimal level of production to keep open the possibility of relying on the coal in case of crisis or a considerable increase in the price of crude oil. For Spain, this level of production was established as 9.12 million tons in 2012, and though at present the new National Plan of Coal (2013-2018) is being developed, the principal aim is to allow the continuity of the Spanish developments.

Obtaining the existing reserves requires using levels of mechanisation of labour that allow economic competitiveness as well as safety within the context of the regulation RGNBSM (General Regulation of Basic Procedure of Mining safety, 1985) [3]. In this regard, methods of excavation in longwall mining using individual hydraulic support elements (mechanical props) have special importance (Figure 1). This mining method is commonly used in the coal-bearing deposits of Castilla-Leon in the north of Spain [4].

But longwall mining is not a new approach to coal mining. In fact, the basic principles of longwall mining have been traced back to the latter part of the 17th century, to Shropshire and other counties in England [5]. In the United States, longwall mining is actually 50 percent of the underground coal production [6-8], with 49 operating longwalls producing over 175 million tonnes per year [7]. Besides USA, among the most productive longwalls are those in Australia and the Shenhua coalfield in China. Shenhua was developed from a green-field site in 1992 and now has more than seven major underground mines producing over 200 million tonnes per year. Australia has 29 operating faces with a total longwall production of 47.5 million tonnes. 

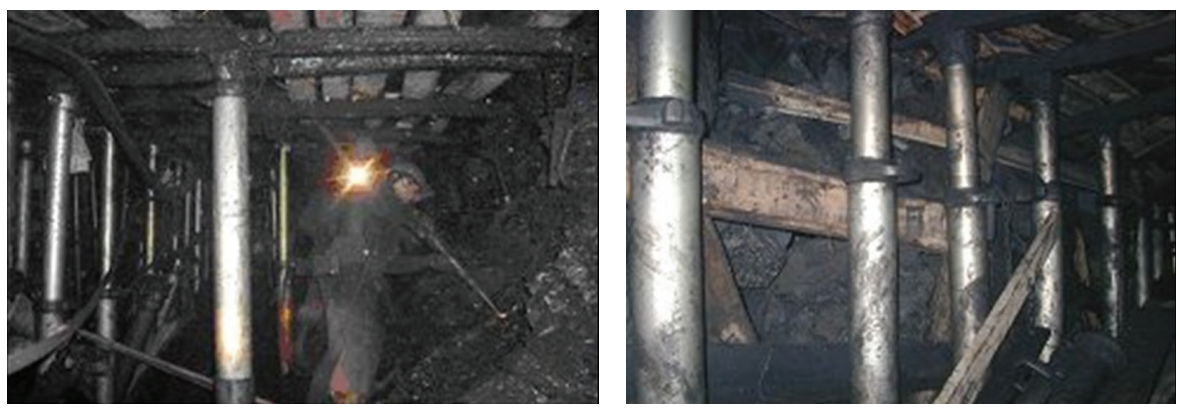

FIGURE 1: Mining labour supported by individual hydraulic props.

\section{Engineering Background}

Longwall mining $[9,10]$, for panels of coal, is an exploitation method where an extended wall of coal is mined in a sole slice. The wall or longwall is around 150-300 $\mathrm{m}$ long and 1$2 \mathrm{~m}$ thick, and the slab of coal that is being mined is around 1000-3500 $\mathrm{m}$ long and 150-300 m broad. The coal is removed from the wall by shearing machinery, which travels back and forth across the coalface, and load the coal onto a conveyor belt that carries it out of the mine. The area immediately in front of the coalface is supported by a series of hydraulic roof supports, which temporarily hold up the roof strata and provide a working space for the shearing machinery, the face conveyor and of course the mines. After each slice of coal is removed, the hydraulic roof supports, the face conveyor, and the shearing machinery are moved forward.

From that moment, the roof immediately above the seam is allowed to collapse into the void that is left as the face retreats. Miners working along the coalface, operating the machinery, are shielded from the collapsing strata by the canopy of the hydraulic roof supports. As the roof collapses into the goaf behind the roof supports, the fracturing and settlement of the rocks progresses through the overlying strata and results in sagging and bending of the near surface rocks and in some cases subsidence of the ground above [11].

Mechanised longwall mining is ever changing and evolving with new techniques, technology, equipment, face management practices, and systems appearing as a direct means to continually improve all aspects of operational and financial performances [12].

Nevertheless, and in spite of the importance of this method of exploitation, no legal regulation exists regarding the types of support and thickness and characteristics of the rock mass surrounding the excavation, which would guarantee the safe functioning of these developments.

Calculation of the pressure that the working roof wall is to exert on hydraulic props is essential for support design, both to ensure working global stability and to avoid prop punching on gables [13]. These two concepts are analysed in multiple papers, as are the behaviour of the overlying rock strata and the performance of the support. R. Singh and T. N. Singh [14] verified the influence that the additional load on the chock shield was exercising by the broken rock mass in thick seams, with values of limiting span given by the clamped and cantilever beam equations. Ju and $\mathrm{Xu}$ [15] analysed the strata behaviour during the operation of great mining height, studying the structural characteristics of key strata (cantilever beam and/or voussoir beam) as well as the movement law. Bilim and Özkan [16] analysed the effect of excavation schedules on the overlying rock strata and the supports. González-Nicieza et al. [17] and Juárez-Ferreras et al. $[18,19]$ analysed the maximum pressure that the coal hanging wall and footwall are capable of supporting, as well as the density of the props and the conditions of the supports they are resting on so that penetration of the props does not occur.

This work tries to contribute to an advance in the design and optimisation of the roof support in longwall mining, analysing the stability of the roof with a method based on the resistance of materials [20] from the characteristics of the roof materials.

In addition, two very important aspects of the safety and the productivity of the exploitation have been considered: the dimensions and the number of walkways of the panel. The width of the rear walkway at waist level needs to be considered from an ergonomic aspect to allow for lamps and self-rescuers worn by underground personnel. The horizontal dimension across an average person's waist is between 620 and $700 \mathrm{~mm}$, so a rear walkway width of $\geq 750 \mathrm{~mm}$ at waist height is required to permit ergonomically effective passage of people along the face so their productivity is not unnecessarily impeded [12]. The number of walkways impacts the safety of the panels and their productivity due to the fact that it produces variations in the bending moment and deflection laws.

\section{Exposition of the Problem}

It is considered as a longwall exploitation (Figure 2) if the two dimensions according to the $X$ and $Z$ axes are very large in comparison with the height or dimension along the $Y$ axis. For simplicity, in this paper we consider a length of the workshop $b$ to be equal to $1 \mathrm{~m}$ in the $Z$ direction. The supporting hydraulic elements divide the panel into sections or spans; in each span, the following characteristics are considered constants:

(i) length: $L_{i}(\mathrm{~m})$;

(ii) Young's modulus: $E_{i}(\mathrm{~Pa})$;

(iii) thickness: $e_{i}(\mathrm{~m})$;

(iv) load: $q_{i}(\mathrm{~N} / \mathrm{m})$. 


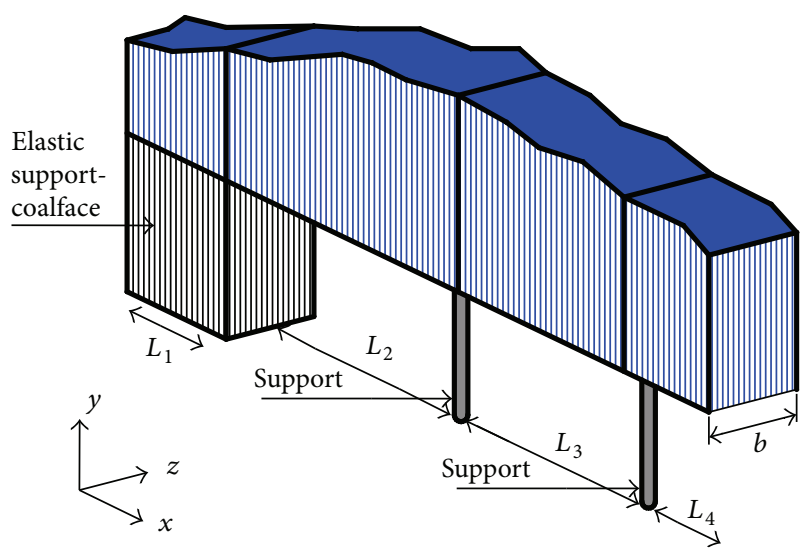

Figure 2: Scheme of longwall mining.

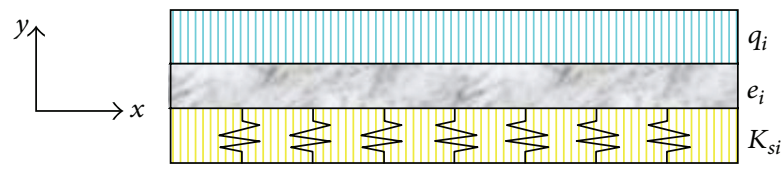

FIgURE 3: Single section.

In addition, it is considered that the stiffness $k_{e}$ of the supporting elements can be different and it is possible that there exist other supporting elements with stiffness $K_{s}$, for example, keys of wood, the coalface, or the protection rock mass between two panels. So, each span, besides the properties previously indicated, presents the following:

(i) stiffness of the uniform support: $K_{s i}(\mathrm{~Pa})$;

(ii) stiffness of the props: $K_{e i}(\mathrm{~Pa})$.

Along with these assumptions is imposed the restriction that within each span the roof rock is perfectly elastic, homogeneous, and isotropic and the neutral axis coincides with the centre line of the thickness.

Considering each roof of a span as a beam subjected to a uniformly distributed load, $q_{i}$, acting in the principal plane of the symmetric cross-section (Figure 3), the deflection of this roof is described through a differential equation of fourth degree [20]:

$$
K_{t i} \cdot y_{i}^{I V}+K_{s i} \cdot y_{i}=q_{i},
$$

where $y_{i}$ is the deflection in each point and $K_{t i}$ is a constant given by the expression $K_{t i}=E_{i} \cdot I_{i}$. with $I_{i}$ the moment of inertia.

The solution of the differential equation (1) is given by

$$
\begin{aligned}
y_{i}(x)= & e^{K_{i} \cdot x} \cdot\left(A_{i} \cdot \cos K_{i} \cdot x+B_{i} \cdot \sin K_{i} \cdot x\right) \\
& +e^{-K_{i} \cdot x} \cdot\left(C_{i} \cdot \cos K_{i} \cdot x+D_{i} \cdot \sin K_{i} \cdot x\right)+y_{p i},
\end{aligned}
$$

where $K_{i}$ and $y_{p i}$ are given by the expressions $K_{i}=\left(K_{s i} /\right.$ $\left.K_{t i}\right)^{0.25}$, and $y_{p i}=q_{i} / K_{s i}$, respectively, and $A_{i}, B_{i}, C_{i}$, and $D_{i}$, are constants that must be determined using the boundary conditions, which constitute the unknown quantities of the problem.

Once the deflection is obtained, the angle of rotation at any point of the panel is given by the first derivative of the deflection $\left(\theta_{i}(x)=y_{i}^{\prime}(x)\right)$ :

$$
\begin{aligned}
\theta_{i}(x)= & K_{i} \cdot e^{K_{i} \cdot x} \\
& \cdot\left[\left(A_{i}+B_{i}\right) \cdot \cos K_{i} \cdot x+\left(-A_{i}+B_{i}\right) \cdot \sin K_{i} \cdot x\right] \\
& +K_{i} \cdot e^{-K_{i} \cdot x} \\
& \cdot\left[\left(-C_{i}+D_{i}\right) \cdot \cos K_{i} \cdot x-\left(C_{i}+D_{i}\right) \cdot \sin K_{i} \cdot x\right] .
\end{aligned}
$$

The bending moment $\left(M_{i}(x)=K_{t i} \cdot y_{i}^{\prime \prime}(x)\right)$ and the shear force $\left(V_{i}(x)=-K_{t i} \cdot y_{i}^{\prime \prime \prime}(x)\right)$ at every point of the panel are given by (4) and (5), respectively:

$$
\begin{aligned}
& M_{i}(x) \\
& =K_{t i} \cdot\left[2 \cdot K_{i}^{2} \cdot e^{K_{i} \cdot x} \cdot\left(B_{i} \cdot \cos K_{i} \cdot x-A_{i} \cdot \sin K_{i} \cdot x\right)\right. \\
& +2 \cdot K_{i}^{2} \cdot e^{-K_{i} \cdot x} \\
& \left.\cdot\left(-D_{i} \cdot \cos K_{i} \cdot x+C_{i} \cdot \sin K_{i} \cdot x\right)\right] \text {, } \\
& V_{i}(x) \\
& =-K_{t i} \\
& \cdot\left\{2 \cdot K_{i}^{3} \cdot e^{K_{i} \cdot x}\right. \\
& \cdot\left[\left(-A_{i}+B_{i}\right) \cdot \cos K_{i} \cdot x-\left(A_{i}+B_{i}\right) \cdot \sin K_{i} \cdot x\right] \\
& +2 \cdot K_{i}^{3} \cdot e^{-K_{i} \cdot x} \\
& \left.\cdot\left[\left(C_{i}+D_{i}\right) \cdot \cos K_{i} \cdot x+\left(-C_{i}+D_{i}\right) \cdot \sin K_{i} \cdot x\right]\right\} .
\end{aligned}
$$

As mentioned previously, once the equations that define the problem have been established, it is necessary to determine the boundary conditions (null deflections and null rotations at the ends of the panel) and the conditions of compatibility (equal deflections, rotations, and bending moments in the points between spans) in order to know the constants $A_{i}, B_{i}$, $C_{i}$, and $D_{i}$.

For this purpose, the panel has been analysed in the phase of take-off by two configurations commonly used in the mines of Castilla-León, with two walkways (panel type 1) and with one walkway (panel type 2).

(i) Panel type 1 has two walkways, three elements of support, and six spans (Figure 4), the first and last spans being supported elastically by the coalface;

(ii) Panel type 2 has one walkway, two elements of support, and five spans (Figure 5), and as in the previous case, the first and last spans are supported elastically by the coalface. 


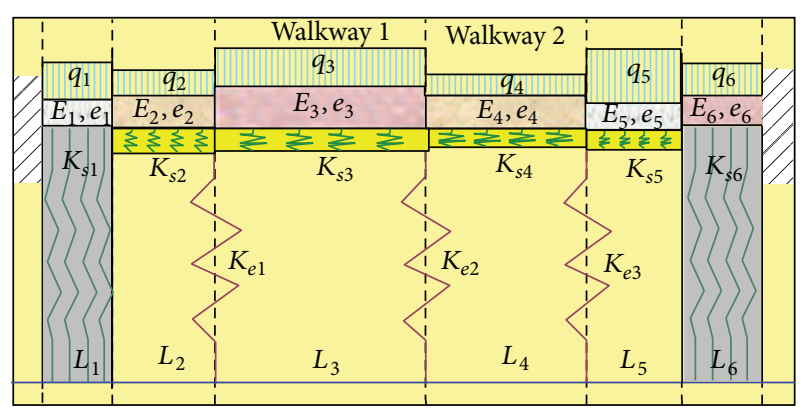

Figure 4: Panel type 1.

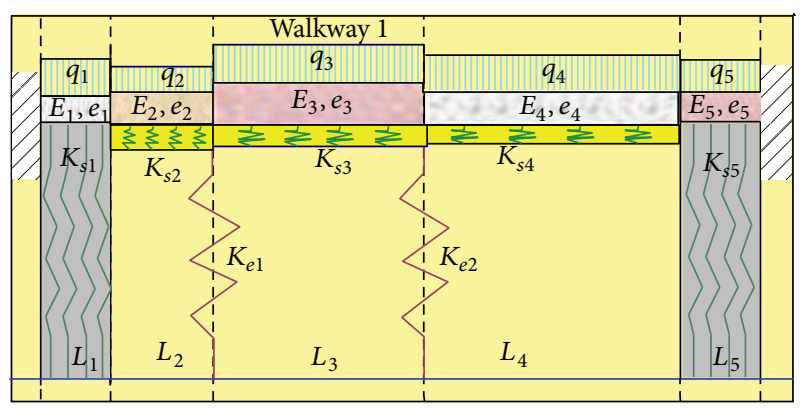

Figure 5: Panel type 2.

The application of the boundary and compatibility conditions gives rise to the system of (6); where $n$ will be 6 for panel type 1 and 5 the panel type 2 .

$$
\begin{gathered}
y_{1}\left(x_{0}\right)=0, \\
y_{1}^{\prime}\left(x_{0}\right)=0, \\
y_{i}\left(x_{i}\right)=y_{i+1}\left(x_{i}\right), \quad i=1,2, \ldots, n-1, \\
y_{i}^{\prime}\left(x_{i}\right)=y_{i+1}^{\prime}\left(x_{i}\right), \quad i=1,2, \ldots, n-1, \\
K_{t i} \cdot y_{i}^{\prime \prime}\left(x_{i}\right)=K_{t i+1} \cdot y_{i+1}^{\prime \prime}\left(x_{i}\right), \quad i=1,2, \ldots, n-1, \\
K_{t i} \cdot y_{1}^{\prime \prime \prime}\left(x_{1}\right)=K_{t i+1} \cdot y_{2}^{\prime \prime \prime}\left(x_{1}\right) \\
K_{t i} \cdot y_{i}^{\prime \prime \prime}\left(x_{i}\right)-K_{t i+1} \cdot y_{1+1}^{\prime \prime \prime}\left(x_{i}\right)=K_{e i} \cdot y_{i}\left(x_{i}\right), \\
\quad i=2, \ldots, n-2, \\
K_{t n-1} \cdot y_{n-1}^{\prime \prime \prime}\left(x_{n-1}\right)=K_{t n} \cdot y_{n}^{\prime \prime \prime}\left(x_{n-1}\right), \\
y_{n}\left(x_{n}\right)=0, \\
y_{n}^{\prime}\left(x_{n}\right)=0,
\end{gathered}
$$

where

$$
x_{i}=\sum_{j=1}^{i} L_{i}, \quad i=1,2, \ldots, n .
$$

Replacing the values of the deflection and its derivatives in (6) and expressing the system in matrix form, the following is obtained:

$$
M \cdot U=B,
$$

where the transposed matrix of $U$ is given by

$$
{ }^{T} U=\left[\begin{array}{llll}
{ }^{T} U_{1} & { }^{T} U_{2} & \cdots & { }^{T} U_{n}
\end{array}\right],
$$

where

$$
{ }^{T} U_{i}=\left[\begin{array}{llll}
A_{i} & B_{i} & C_{i} & D_{i}
\end{array}\right], \quad i=1,2, \ldots, n .
$$

Therefore, the not null elements of the matrices $M_{(4 n \times 4 n)}=$ $\left\{m_{i j}\right\}$ and $B_{(4 n \times 1)}=\left\{b_{i}\right\}$ are obtained (the Appendix) for the panel type 1 . In panel type 2 , the matrixes $M$ and $B$ are equal to the first type in its first 14 rows, with the last ones also being equal with the exception of the following changes of indexes: indexes 5 and 6 of the problem type 1 transform into the indexes 4 and 5, respectively, of the problem type 2 .

\section{Calculating the Factor of Safety of the Workshop}

Once the efforts have been calculated, it is possible to calculate the factor of safety (FS) of the panel dividing the tensile strength of each section $\left(\sigma_{t}(x)\right)$ for the normal stress $(\sigma(x))(14)$. If this coefficient is bigger than one, the roof of the panel is capable of supporting the stresses to which it is subjected, and, therefore, the work is realised in safe conditions.

To calculate this FS in each section of the roof, the shear stress (11) and the bending stress (12) are calculated as follows:

$$
\begin{aligned}
\tau(x) & =\frac{4 \cdot V(x)}{3 \cdot e \cdot b}, \\
\sigma_{f}(x) & =\frac{6 \cdot M(x)}{b \cdot e^{2}} .
\end{aligned}
$$

From (11) and (12), the normal stress is calculated as

$$
\sigma(x)=0.5 \cdot\left[\sigma_{f}(x)+\sqrt{\sigma_{f}^{2}(x)+4 \cdot \tau^{2}(x)}\right] .
$$

Once the stresses are calculated, the FS is given by

$$
\mathrm{FS}=\frac{\sigma_{t}(x)}{\sigma(x)} .
$$

\section{Practical Case}

A panel in the take-off phase is analysed with two configurations commonly used in the mines of Castilla-León and more specifically in the Feixolin mine [17], with two walkways (panel type 1) and with one walkway (panel type 2). Figures 4 and 5 show that in the phase of take-off, the first and last spans rest elastically on the coal, whereas the halfway sections rest on siltstone with an apparent density of $2.75 \mathrm{t} / \mathrm{m}^{3}$. The hydraulic props are of the type EA 25 manufactured by Salzgitter and reach a maximum extend length of $2.5 \mathrm{~m}$. 


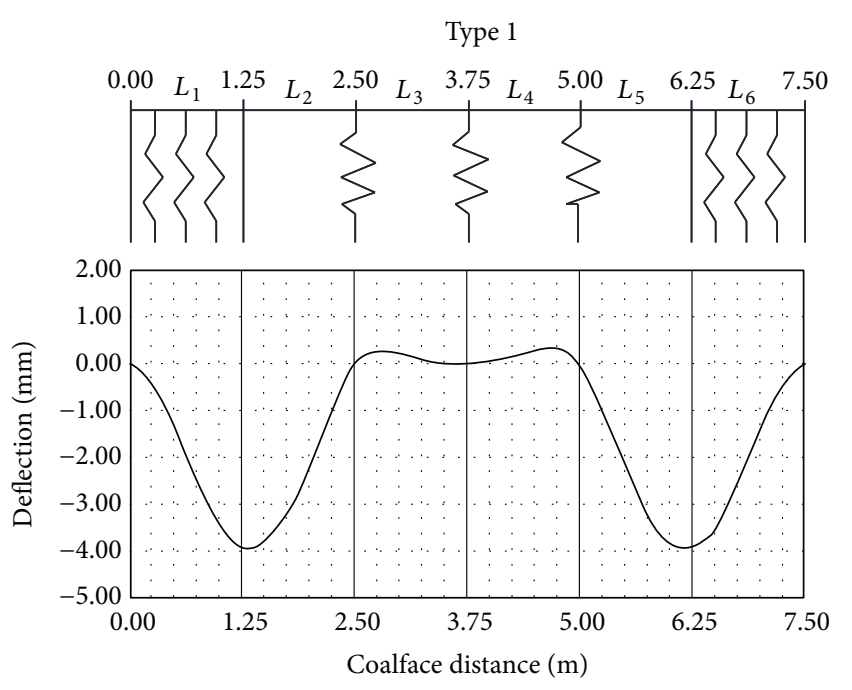

(a)

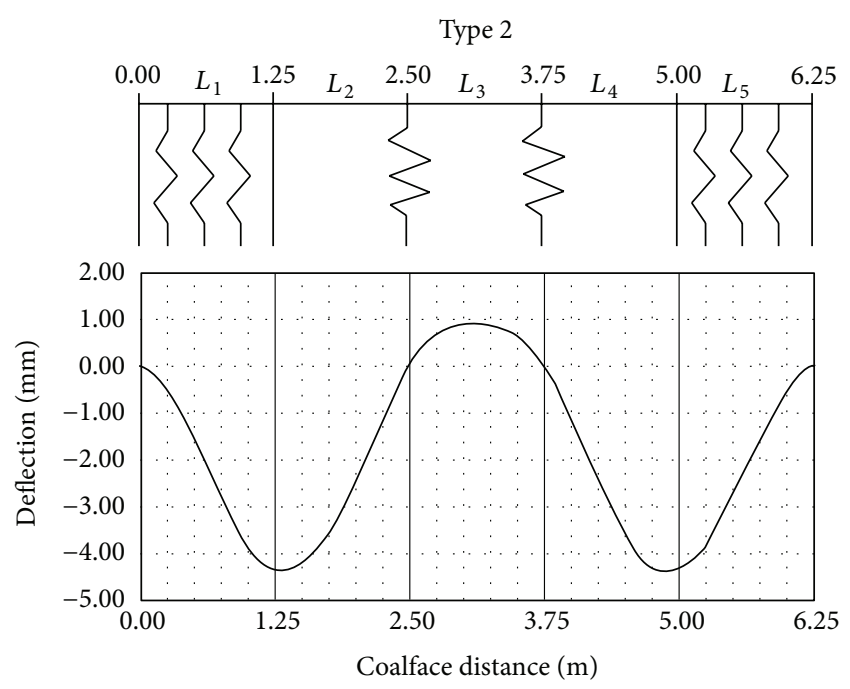

(b)

Figure 6: Deflection.

To calculate the stiffness of the siltstone, the pressures obtained in the penetration test are considered, and to calculate the stiffness of the props [21], the load-deformation curves from the load plate test are used. All of these calculations were for the Feixolin mine [17]. Table 1 shows the properties used in the analysis.

One of the most important parameters from the safety point of view as well as in terms of accessibility is the deflection of the roof. In this case, it is considered that negative values of the deflection are equivalent to an increase of the deflection and vice versa.

As it is observed in Figure 6 for both configurations analysed, there is a symmetrical deflection from the centre with a shape very similar to that of a bifixed beam, though in this case the curve does not increase progressively to reach a maximum deflection in the centre. On the contrary, several segments are distinguished in the curve. These segments coincide with the changes of spans of the panel. The first and last spans ( 1 and 6 in panel type 1 and 1 and 5 in panel type 2) present an increase of the deflection reaching the maximum at the edge of the span, that is, at the edge of the elastic support. These maximum values of deflection are $-3.98 \mathrm{~mm}$ for panel type 1 and $-4.39 \mathrm{~mm}$ for panel type 2 . At this point, the presence of hydraulic props produces a decrease in the value of the deflection, even from negative values that indicate that the roof turns down to positive values at spans 3 and 4 of panel type 1 . These positive values are due to the pressure in the opposite direction to the deflection, which is realised by the supports. The deflection descends to $0.31 \mathrm{~mm}$ being null in the middle of the workshop. On the contrary, in panel type 2 , the decrease of the deformation is constant until the minimum is reached in the middle point of span 3 , with $0.96 \mathrm{~mm}$.

In any case, the deflection of the roof can be considered low and barely affects working conditions.

The fall of the roof, that is, the increase of its deflection, depends directly on the stiffness of the hydraulic props. As it

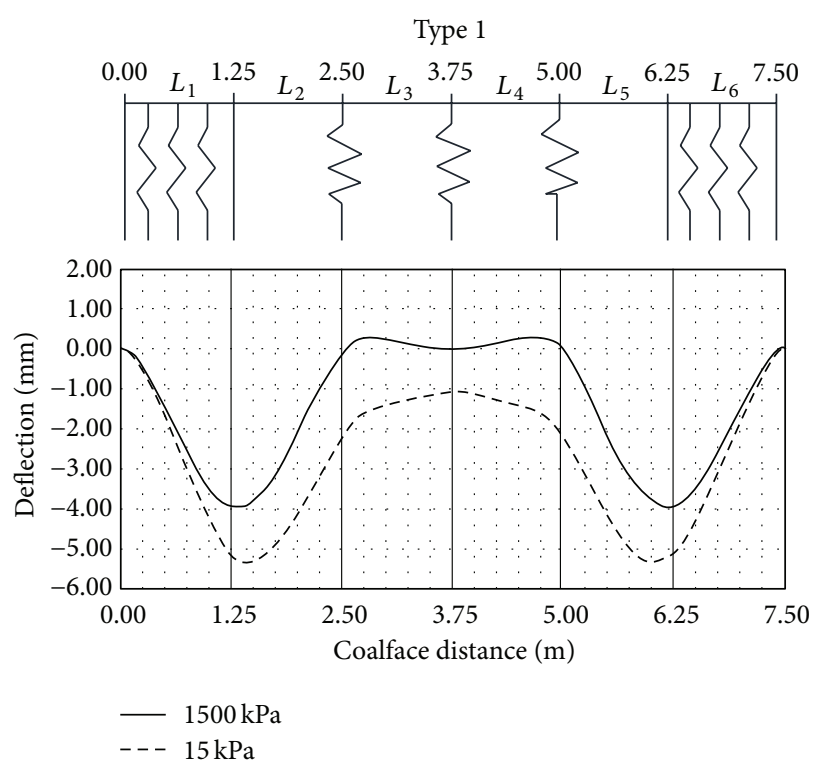

Figure 7: Deflection with stiffness of props 100 times minors.

is observed in Figure 7, with a stiffness of the props 100 times less, similar curves are obtained. Nevertheless, the values of deflection in the ends of the first spans are major $(-5.35 \mathrm{~mm})$. On the other hand, the decrease of this deflection is minor not reaching positive values at any time. This is due to the fact that in these conditions the capacity of support is for the roof and not for the hydraulic props.

On the contrary, considering an increase in the stiffness of the hydraulic props, it does not suppose a change over the results obtained in the initial conditions (Figure 6). This is because the stiffness of the props initially is so big compared to the stiffness of the rest of the materials that an increase of its value does not produce any effect. 
TABle 1: Properties of the materials in each section or span.

\begin{tabular}{|c|c|c|c|c|c|c|}
\hline & $\begin{array}{l}\text { Section } 1 \\
\text { siltstone }\end{array}$ & $\begin{array}{l}\text { Section } 2 \\
\text { siltstone }\end{array}$ & $\begin{array}{l}\text { Section } 3 \\
\text { siltstone }\end{array}$ & $\begin{array}{l}\text { Section } 4 \\
\text { siltstone }\end{array}$ & $\begin{array}{l}\text { Section } 5 \\
\text { siltstone }\end{array}$ & $\begin{array}{l}\text { Section } 6 \\
\text { siltstone }\end{array}$ \\
\hline Length of span (m) & 1.25 & 1.25 & 1.25 & 1.25 & 1.25 & 1.25 \\
\hline Thickness (m) & 1.5 & 1.5 & 1.5 & 1.5 & 1.5 & 1.5 \\
\hline Young's modulus (MPa) & 3550 & 3550 & 3550 & 3550 & 3550 & 3550 \\
\hline Load $(\mathrm{kN} / \mathrm{m})$ & 17200 & 17200 & 17200 & 17200 & 17200 & 17200 \\
\hline Supporting stiffness $(\mathrm{MPa} / \mathrm{m})$ & 47.8 & 47.8 & 47.8 & 47.8 & 47.8 & 47.8 \\
\hline Tensile strength (MPa) & 4.24 & 4.24 & 4.24 & 4.24 & 4.24 & 4.24 \\
\hline Prop number & \multicolumn{2}{|c|}{1} & \multicolumn{2}{|c|}{2} & \multicolumn{2}{|c|}{3} \\
\hline Prop stiffness $(\mathrm{MPa} / \mathrm{m})$ & \multicolumn{2}{|c|}{1500} & \multicolumn{2}{|c|}{1500} & \multicolumn{2}{|c|}{1500} \\
\hline Spacing of props (m) & \multicolumn{2}{|c|}{0.55} & \multicolumn{2}{|c|}{0.55} & \multicolumn{2}{|c|}{0.55} \\
\hline
\end{tabular}

The bending moment (Figure 8) shows symmetrical curves to the deflection ones. In this case, the maximum values for panels type 1 and type 2 are $5.05 \mathrm{kNm}$ and $5.38 \mathrm{kNm}$, respectively. The maximum values are at the edges of the elastic supports, whereas the minimum values occur at the points of placement of the hydraulic props.

In this case, a decrease of the stiffness of the props does not produce a change in the shape of the curves and only produces small variations in the maximum values obtained (panel type 1: $5.24 \mathrm{kNm}$, and panel type 2: $5.50 \mathrm{kNm}$ ).

A change in the materials of the roof does not alter the shape of the curve, but it modifies the maximum and minimum values, which does not happen with the deflection. This behaviour is due to how the bending moment is obtained (4), multiplying the second derivative of the deflection by a constant for each section, $K_{t i}$. For spans of equal thickness, $K_{t i}$ is directly proportional to Young's modulus of the material of the span.

The representation of the rotation angle of the spans produces symmetrical curves from the centre of the panel, as much in the case of type 1 as type 2. In Figure 9, it is observed that the use of props produces fluctuations in the rotation, but always reaching lower values to those presented for zones close to the extremes. The maximum rotation is around 4.79 radians in panel type 1 and 5 radians in panel type 2 .

The shear force (Figure 10) presents jumps of values in those spans where the hydraulic props are placed. These maximum values (in absolute value) are in the second and last and the values reached as much in panel type 1 as in panel type 2 are very similar and around $20 \mathrm{kN}$.

Although most of the parameters shown in Table 1 depend on the type of rock, there are some of them that can vary. The type of support, hence its stiffness (Figure 6), as well as the length of the spans, is a compromise between the safety and the productivity of the panel. While the depth of the panel, that is, the load per unit of length, will increase over time, the exploitation advances.

A decrease in the length of the spans (Figure 11) decreases the value of all the parameters analysed: deflection, rotation angle, bending moment, and shear force. However, decreasing this value means, on the one hand, placing a bigger number of props, thus increasing the cost of production, and on the other reduce the space step for miners. In any case, this length cannot be less than $0.75 \mathrm{~m}$ considering all the equipment that the miners wear around their body.

An increase in the length of the spans increases the value of all parameters and specifically the value of the deflection. So it is necessary to find a compromise between length and safety/productivity.

With the advance in the exploitation, the depth of the panels grows and therefore the load on spans increases. This increase results in a greater deflection of the roof (Figure 12) and also an increase of the bending moment and of the shear force.

The analysed parameters, and specifically the shear force and the bending moment, let us know one of the most important points in the design of a panel of longwall: the FS. In the two examples with the properties shown in Table 1, the values of the FS are bigger than 5 . That is to say, the studied mine is safe for this design. Nevertheless, it is possible to determine in what spans and in what type of panel a minor FS is produced.

From (14), it is possible to deduce that the FS is directly proportional to the tensile strength and inversely proportional to the sum of the bending moment and the shear force. The variation of the values of the bending moment and shear force (Figures 8 and 10) indicates that the most critical points, in the analysis of the safety, are at the edges of the elastic supports (the borders of the first and last span).

The influence of the distribution of the props, their stiffness, or the number of walkways in the panel over the FS has been analysed. Nevertheless, unless extreme values were used, the FS scarcely varied in its value. On the contrary, changes in the properties of the materials, and especially changes in the Young's modulus, produce great variations in the FS.

\section{Conclusions}

(i) The calculation of the stability of roofs in longwall mining can be resolved by employing the classic resistance of materials.

(ii) In addition, because the calculation process is very fast, it is possible to design a more appropriate roof support for a specific longwall mining workshop, to 


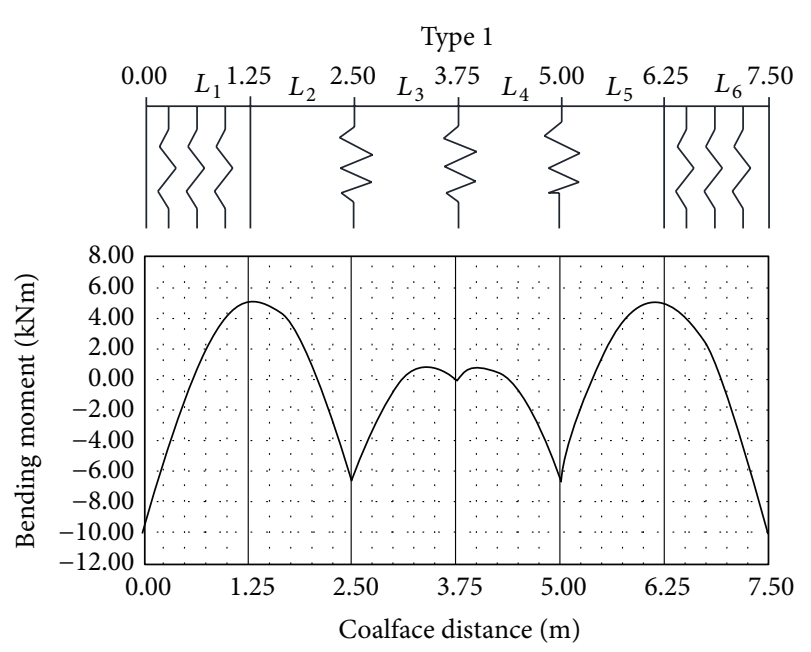

(a)

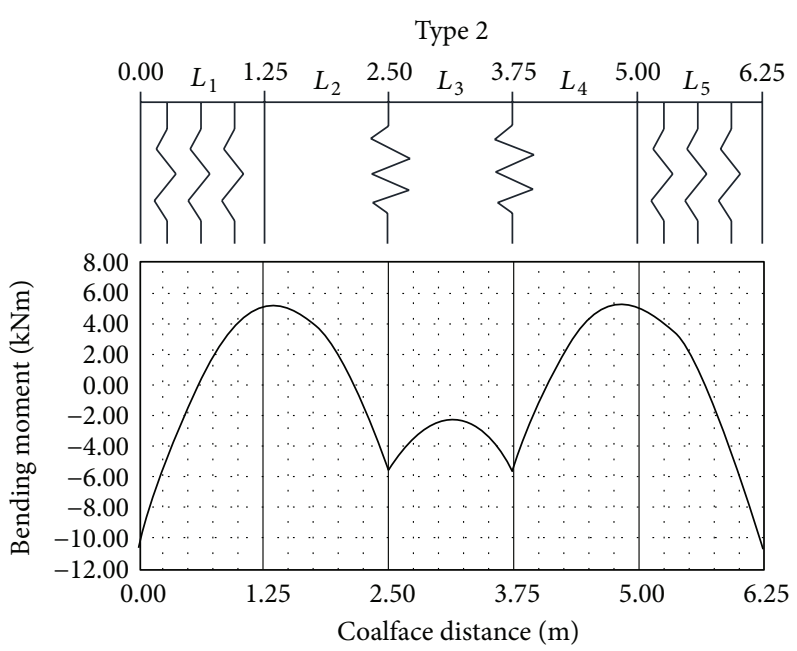

(b)

Figure 8: Bending moment.

Type 1

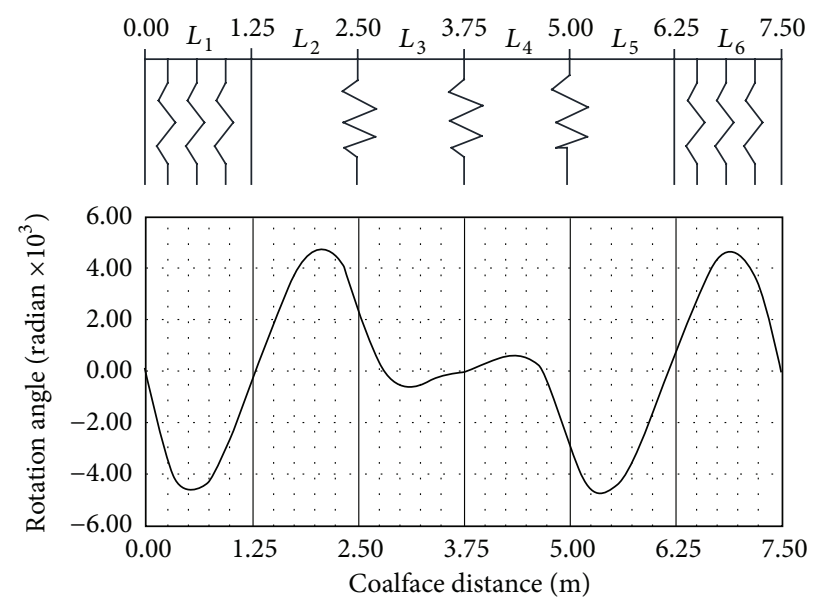

(a)

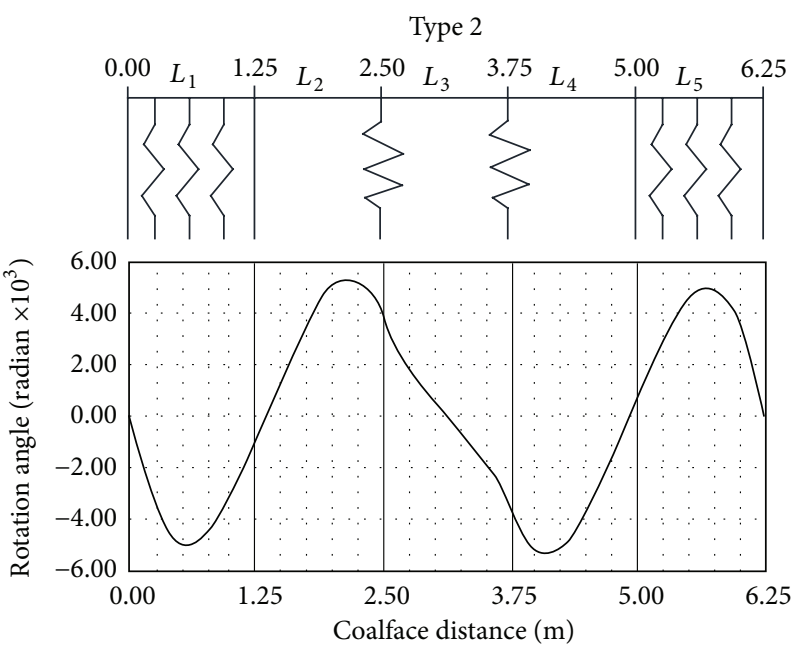

(b)

FIGURE 9: Rotation angle.

know the behaviour of the roof as a support element, and to analyse the influence and capacity of the individual support elements and the effect of their longitudinal and transverse spacing.

(iii) While the most influential factor in the deflection of the roof is the stiffness of the props, the bending moment depends directly on the properties of the materials and specifically on their Young's modulus.

(iv) In all cases, the disposition of two walkways in the panel against one walkway reduces the maximum values of the parameters analysed with the exception of the shear force. In any case, these maximum values are placed, for both configurations analysed, in the second and last but one sections. So, these sections are critical in the analysis of the FS. (v) Finally, the variables that have most influence in the FS, are undoubtedly the depth of the panel and above all the changes in the properties of the rock mass of the roof.

\section{Highlights}

(i) Analyse the influence that the dimensions and the number of walkways of the panel have on the stability of the roof.

(ii) Study the influence of not only the individual elements of support but also the coalface, which is considered one more supporting element.

(iii) Analyse the configuration of the support (longitudinal and transverse spacing) in longwall mining.

(iv) Know in a simple way the safety factor for a workshop. 
Type 1

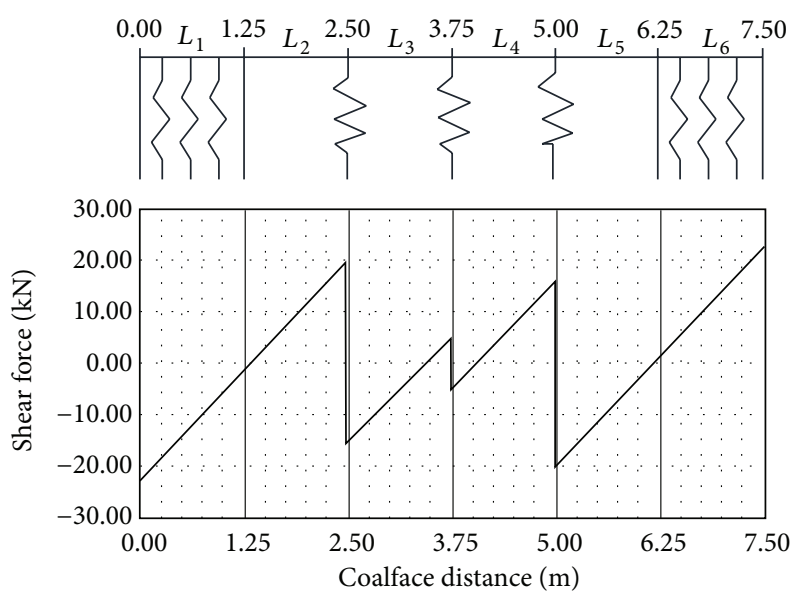

(a)

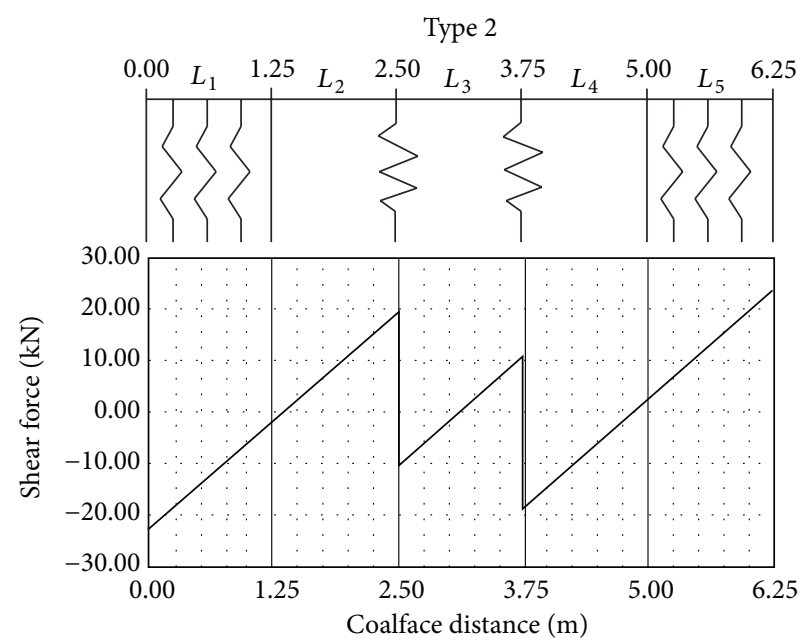

(b)

Figure 10: Shear force.

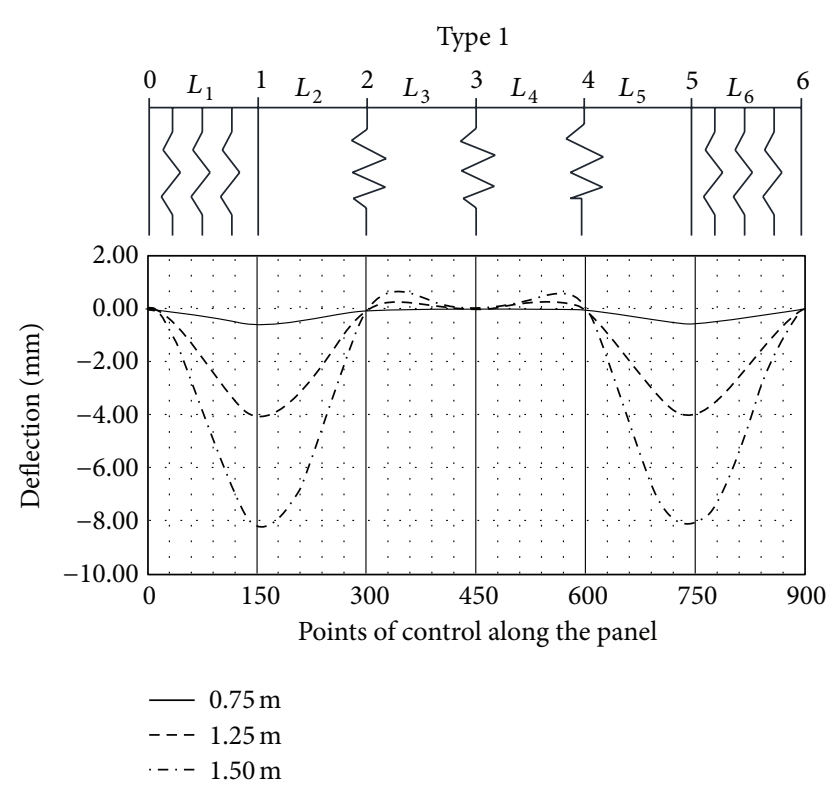

FIGURE 11: Deflection versus length of spans.

\section{Appendix}

The not null elements of the matrices $M_{(24 \times 24)}=\left\{m_{i j}\right\}$ and $B_{(24 \times 1)}=\left\{b_{i}\right\}$ of the problem type 1 are as follows.

Row 1.

$$
\begin{gathered}
m_{1,1}=m_{1,3}=1, \\
b_{1}=-y_{p 1} .
\end{gathered}
$$

Row 2.

$$
\begin{aligned}
& m_{2,1}=m_{2,2}=m_{2,4}=1, \\
& m_{2,3}=-1 .
\end{aligned}
$$

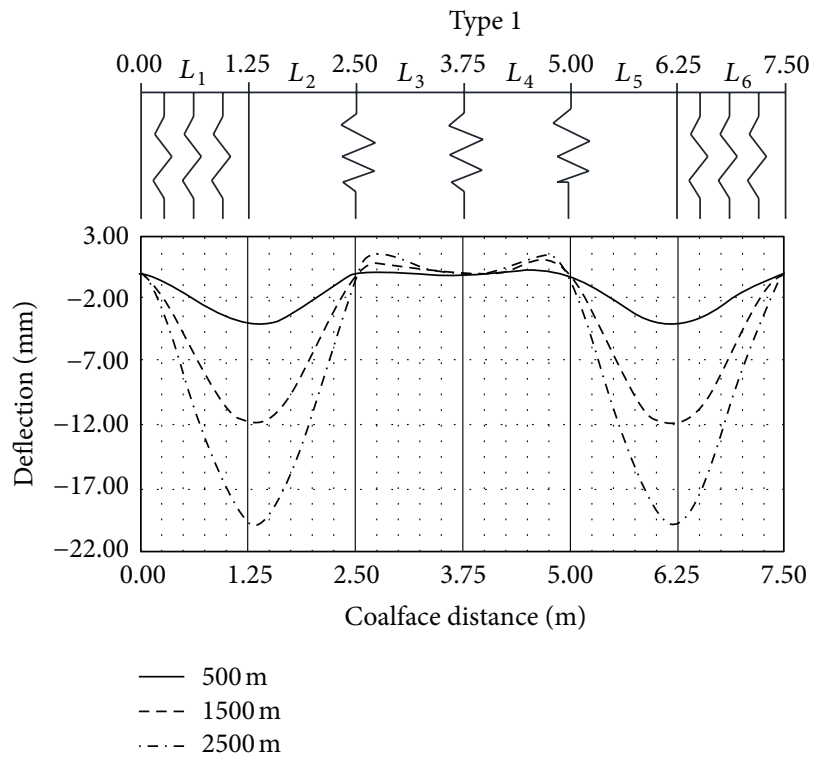

FIGURE 12: Deflection versus depth of the panel.

Row 3.

$$
\begin{aligned}
& m_{3,1}=e^{K_{1} x_{1}} \cdot \cos K_{1} x_{1}, \\
& m_{3,2}=e^{K_{1} x_{1}} \cdot \sin K_{1} x_{1}, \\
& m_{3,3}=e^{-K_{1} x_{1}} \cdot \cos K_{1} x_{1}, \\
& m_{3,4}=e^{-K_{1} x_{1}} \cdot \sin K_{1} x_{1}, \\
& m_{3,5}=-e^{K_{2} x_{1}} \cdot \cos K_{2} x_{1}, \\
& m_{3,6}=-e^{K_{2} x_{1}} \cdot \sin K_{2} x_{1}, \\
& m_{3,7}=-e^{-K_{2} x_{1}} \cdot \cos K_{2} x_{1},
\end{aligned}
$$




$$
\begin{aligned}
m_{3,8} & =-e^{-K_{2} x_{1}} \cdot \sin K_{2} x_{1}, \\
b_{3} & =y_{p 2}-y_{p 1} .
\end{aligned}
$$

Row 4.

$$
\begin{aligned}
& m_{4,1}=K_{1} e^{K_{1} x_{1}}\left(\cos K_{1} x_{1}-\sin K_{1} x_{1}\right), \\
& m_{4,2}=K_{1} e^{K_{1} x_{1}}\left(\cos K_{1} x_{1}+\sin K_{1} x_{1}\right), \\
& m_{4,3}=-K_{1} e^{-K_{1} x_{1}}\left(\cos K_{1} x_{1}+\sin K_{1} x_{1}\right), \\
& m_{4,4}=K_{1} e^{-K_{1} x_{1}}\left(\cos K_{1} x_{1}-\sin K_{1} x_{1}\right), \\
& m_{4,5}=-K_{2} e^{K_{2} x_{1}}\left(\cos K_{2} x_{1}-\sin K_{2} x_{1}\right), \\
& m_{4,6}=-K_{2} e^{K_{2} x_{1}}\left(\cos K_{2} x_{1}+\sin K_{2} x_{1}\right), \\
& m_{4,7}=K_{2} e^{-K_{2} x_{1}}\left(\cos K_{2} x_{1}+\sin K_{2} x_{1}\right), \\
& m_{4,8}=-K_{2} e^{-K_{2} x_{1}}\left(\cos K_{2} x_{1}-\sin K_{2} x_{1}\right)
\end{aligned}
$$

Row 5.

$$
\begin{aligned}
& m_{5,1}=-2 K_{1}^{2} e^{K_{1} x_{1}} \sin K_{1} x_{1}, \\
& m_{5,2}=2 K_{1}^{2} e^{K_{1} x_{1}} \cos K_{1} x_{1}, \\
& m_{5,3}=2 K_{1}^{2} e^{-K_{1} x_{1}} \sin K_{1} x_{1}, \\
& m_{5,4}=-2 K_{1}^{2} e^{-K_{1} x_{1}} \cos K_{1} x_{1}, \\
& m_{5,5}=2 K_{2}^{2} e^{K_{2} x_{1}} \sin K_{2} x_{1}, \\
& m_{5,6}=-2 K_{2}^{2} e^{K_{2} x_{1}} \cos K_{2} x_{1}, \\
& m_{5,7}=-2 K_{2}^{2} e^{-K_{2} x_{1}} \sin K_{2} x_{1}, \\
& m_{5,8}=2 K_{2}^{2} e^{-K_{2} x_{1}} \cos K_{2} x_{1} .
\end{aligned}
$$

Row 6.

$$
\begin{aligned}
& m_{6,1}=-2 K_{1}^{3} e^{K_{1} x_{1}}\left(\cos K_{1} x_{1}+\sin K_{1} x_{1}\right), \\
& m_{6,2}=2 K_{1}^{3} e^{K_{1} x_{1}}\left(\cos K_{1} x_{1}-\sin K_{1} x_{1}\right), \\
& m_{6,3}=2 K_{1}^{3} e^{-K_{1} x_{1}}\left(\cos K_{1} x_{1}-\sin K_{1} x_{1}\right), \\
& m_{6,4}=2 K_{1}^{3} e^{-K_{1} x_{1}}\left(\cos K_{1} x_{1}+\sin K_{1} x_{1}\right), \\
& m_{6,5}=2 K_{2}^{3} e^{K_{2} x_{1}}\left(\cos K_{2} x_{1}+\sin K_{2} x_{1}\right), \\
& m_{6,6}=-2 K_{2}^{3} e^{K_{2} x_{1}}\left(\cos K_{2} x_{1}-\sin K_{2} x_{1}\right), \\
& m_{6,7}=-2 K_{2}^{3} e^{-K_{2} x_{1}}\left(\cos K_{2} x_{1}-\sin K_{2} x_{1}\right), \\
& m_{6,8}=-2 K_{2}^{3} e^{-K_{2} x_{1}}\left(\cos K_{2} x_{1}+\sin K_{2} x_{1}\right) .
\end{aligned}
$$

Row 7.

$$
\begin{aligned}
m_{7,5} & =e^{K_{2} x_{2}} \cdot \cos K_{2} x_{2}, \\
m_{7,6} & =e^{K_{2} x_{2}} \cdot \sin K_{2} x_{2}, \\
m_{7,7} & =e^{-K_{2} x_{2}} \cdot \cos K_{2} x_{2}, \\
m_{7,8} & =e^{-K_{2} x_{2}} \cdot \sin K_{2} x_{2}, \\
m_{7,9} & =-e^{K_{3} x_{2}} \cdot \cos K_{3} x_{2}, \\
m_{7,10} & =-e^{K_{3} x_{2}} \cdot \sin K_{3} x_{2}, \\
m_{7,11} & =-e^{-K_{3} x_{2}} \cdot \cos K_{3} x_{2}, \\
m_{7,12} & =-e^{-K_{3} x_{2}} \cdot \sin K_{3} x_{2}, \\
b_{7} & =y_{p 3}-y_{p 2} \cdot
\end{aligned}
$$

Row 8.

$$
\begin{aligned}
& m_{8,5}=K_{2} e^{K_{2} x_{2}}\left(\cos K_{2} x_{2}-\sin K_{2} x_{2}\right), \\
& m_{8,6}=K_{2} e^{K_{2} x_{2}}\left(\cos K_{2} x_{2}+\sin K_{2} x_{2}\right), \\
& m_{8,7}=-K_{2} e^{-K_{2} x_{2}}\left(\cos K_{2} x_{2}+\sin K_{2} x_{2}\right), \\
& m_{8,8}=K_{2} e^{-K_{2} x_{2}}\left(\cos K_{2} x_{2}-\sin K_{2} x_{2}\right), \\
& m_{8,9}=-K_{3} e^{K_{3} x_{2}}\left(\cos K_{3} x_{2}-\sin K_{3} x_{2}\right), \\
& m_{8,10}=-K_{3} e^{K_{3} x_{2}}\left(\cos K_{3} x_{2}+\sin K_{3} x_{2}\right), \\
& m_{8,11}=K_{3} e^{-K_{3} x_{2}}\left(\cos K_{3} x_{2}+\sin K_{3} x_{2}\right), \\
& m_{8,12}=-K_{3} e^{-K_{3} x_{2}}\left(\cos K_{3} x_{2}-\sin K_{3} x_{2}\right) .
\end{aligned}
$$

Row 9.

$$
\begin{aligned}
& m_{9,5}=-2 K_{2}^{2} e^{K_{2} x_{2}} \sin K_{2} x_{2}, \\
& m_{9,6}=2 K_{2}^{2} e^{K_{2} x_{2}} \cos K_{2} x_{2}, \\
& m_{9,7}=2 K_{2}^{2} e^{-K_{2} x_{2}} \sin K_{2} x_{2}, \\
& m_{9,8}=-2 K_{2}^{2} e^{-K_{2} x_{2}} \cos K_{2} x_{2}, \\
& m_{9,9}=2 K_{3}^{2} e^{K_{3} x_{2}} \sin K_{3} x_{2}, \\
& m_{9,10}=-2 K_{3}^{2} e^{K_{3} x_{2}} \cos K_{3} x_{2}, \\
& m_{9,11}=-2 K_{3}^{2} e^{-K_{3} x_{2}} \sin K_{3} x_{2}, \\
& m_{9,12}=2 K_{3}^{2} e^{-K_{3} x_{2}} \cos K_{3} x_{2} .
\end{aligned}
$$


Row 10.

$$
\begin{aligned}
m_{10,5}= & -2 K_{t 2} K_{2}^{3} e^{K_{2} x_{2}}\left(\cos K_{2} x_{2}+\sin K_{2} x_{2}\right) \\
& -K_{e 1} e^{K_{2} x_{2}} \cos K_{2} x_{2}, \\
m_{10,6}= & 2 K_{t 2} K_{2}^{3} e^{K_{2} x_{2}}\left(\cos K_{2} x_{2}-\sin K_{2} x_{2}\right) \\
& -K_{e 1} e^{K_{2} x_{2}} \sin K_{2} x_{2}, \\
m_{10,7}= & 2 K_{t 2} K_{2}^{3} e^{-K_{2} x_{2}}\left(\cos K_{2} x_{2}-\sin K_{2} x_{2}\right) \\
& -K_{e 1} e^{-K_{2} x_{2}} \cos K_{2} x_{2}, \\
m_{10,8}= & 2 K_{t 2} K_{2}^{3} e^{-K_{2} x_{2}}\left(\cos K_{2} x_{2}+\sin K_{2} x_{2}\right) \\
& -K_{e 1} e^{-K_{2} x_{2}} \sin K_{2} x_{2}, \\
m_{10,9}= & 2 K_{t 3} K_{3}^{3} e^{K_{3} x_{2}}\left(\cos K_{3} x_{2}+\sin K_{3} x_{2}\right), \\
m_{10,10}= & -2 K_{t 3} K_{3}^{3} e^{K_{3} x_{2}}\left(\cos K_{3} x_{2}-\sin K_{3} x_{2}\right), \\
m_{10,11}= & -2 K_{t 3} K_{3}^{3} e^{-K_{3} x_{2}}\left(\cos K_{3} x_{2}-\sin K_{3} x_{2}\right), \\
m_{10,12}= & -2 K_{t 3} K_{3}^{3} e^{-K_{3} x_{2}}\left(\cos K_{3} x_{2}+\sin K_{3} x_{2}\right), \\
b_{10}= & K_{e 1} y_{p 3} .
\end{aligned}
$$

Row 11.

$$
\begin{aligned}
m_{11,9} & =e^{K_{3} x_{3}} \cdot \cos K_{3} x_{3}, \\
m_{11,10} & =e^{K_{3} x_{3}} \cdot \sin K_{3} x_{3}, \\
m_{11,11} & =e^{-K_{3} x_{3}} \cdot \cos K_{3} x_{3}, \\
m_{11,12} & =e^{-K_{3} x_{3}} \cdot \sin K_{3} x_{3}, \\
m_{11,13} & =-e^{K_{4} x_{3}} \cdot \cos K_{4} x_{3}, \\
m_{11,14} & =-e^{K_{4} x_{3}} \cdot \sin K_{4} x_{3}, \\
m_{11,15} & =-e^{-K_{4} x_{3}} \cdot \cos K_{4} x_{3}, \\
m_{11,16} & =-e^{-K_{4} x_{3}} \cdot \sin K_{4} x_{3}, \\
b_{11} & =y_{p 4}-y_{p 3} .
\end{aligned}
$$

Row 12.

$$
\begin{aligned}
& m_{12,9}=K_{3} e^{K_{3} x_{3}}\left(\cos K_{3} x_{3}-\sin K_{3} x_{3}\right), \\
& m_{12,10}=K_{3} e^{K_{3} x_{3}}\left(\cos K_{3} x_{3}+\sin K_{3} x_{3}\right), \\
& m_{12,11}=-K_{3} e^{-K_{3} x_{3}}\left(\cos K_{3} x_{3}+\sin K_{3} x_{3}\right), \\
& m_{12,12}=K_{3} e^{-K_{3} x_{3}}\left(\cos K_{3} x_{3}-\sin K_{3} x_{3}\right), \\
& m_{12,13}=-K_{4} e^{K_{4} x_{3}}\left(\cos K_{4} x_{3}-\sin K_{4} x_{3}\right), \\
& m_{12,14}=-K_{4} e^{K_{4} x_{3}}\left(\cos K_{4} x_{3}+\sin K_{4} x_{3}\right),
\end{aligned}
$$

$$
\begin{aligned}
& m_{12,15}=K_{4} e^{-K_{4} x_{3}}\left(\cos K_{4} x_{3}+\sin K_{4} x_{3}\right), \\
& m_{12,16}=-K_{4} e^{-K_{4} x_{3}}\left(\cos K_{4} x_{3}-\sin K_{4} x_{3}\right) .
\end{aligned}
$$

Row 13.

$$
\begin{aligned}
& m_{13,9}=-2 K_{3}^{2} e^{K_{3} x_{3}} \sin K_{3} x_{3}, \\
& m_{13,10}=2 K_{3}^{2} e^{K_{3} x_{3}} \cos K_{3} x_{3}, \\
& m_{13,11}=2 K_{3}^{2} e^{-K_{3} x_{3}} \sin K_{3} x_{3}, \\
& m_{13,12}=-2 K_{3}^{2} e^{-K_{3} x_{3}} \cos K_{3} x_{3}, \\
& m_{13,13}=2 K_{4}^{2} e^{K_{4} x_{3}} \sin K_{4} x_{3}, \\
& m_{13,14}=-2 K_{4}^{2} e^{K_{4} x_{3}} \cos K_{4} x_{3}, \\
& m_{13,15}=-2 K_{4}^{2} e^{-K_{4} x_{3}} \sin K_{4} x_{3}, \\
& m_{13,16}=2 K_{4}^{2} e^{-K_{4} x_{3}} \cos K_{4} x_{3} .
\end{aligned}
$$

Row 14.

$$
\begin{aligned}
m_{14,9}= & -2 K_{t 3} K_{3}^{3} e^{K_{3} x_{3}}\left(\cos K_{3} x_{3}+\sin K_{3} x_{3}\right) \\
& -K_{e 2} e^{K_{3} x_{3}} \cos K_{3} x_{3}, \\
m_{14,10}= & 2 K_{t 3} K_{3}^{3} e^{K_{3} x_{3}}\left(\cos K_{3} x_{3}-\sin K_{3} x_{3}\right) \\
& -K_{e 2} e^{K_{3} x_{3}} \sin K_{3} x_{3}, \\
m_{14,11}= & 2 K_{t 3} K_{3}^{3} e^{-K_{3} x_{3}}\left(\cos K_{3} x_{3}-\sin K_{3} x_{3}\right) \\
& -K_{e 2} e^{-K_{3} x_{3}} \cos K_{3} x_{3}, \\
m_{14,12}= & 2 K_{t 3} K_{3}^{3} e^{-K_{3} x_{3}}\left(\cos K_{3} x_{3}+\sin K_{3} x_{3}\right) \\
& -K_{e 2} e^{-K_{3} x_{3}} \sin K_{3} x_{3}, \\
m_{14,13}= & 2 K_{t 4} K_{4}^{3} e^{K_{4} x_{3}}\left(\cos K_{4} x_{3}+\sin K_{4} x_{3}\right), \\
m_{14,14}= & -2 K_{t 4} K_{4}^{3} e^{K_{4} x_{3}}\left(\cos K_{4} x_{3}-\sin K_{4} x_{3}\right), \\
m_{14,15}= & -2 K_{t 4} K_{4}^{3} e^{-K_{4} x_{3}}\left(\cos K_{4} x_{3}-\sin K_{4} x_{3}\right), \\
m_{14,16}= & -2 K_{t 4} K_{4}^{3} e^{-K_{4} x_{3}}\left(\cos K_{4} x_{3}+\sin K_{4} x_{3}\right), \\
b_{14}= & K_{e 2} y_{p 3} .
\end{aligned}
$$

Row 15.

$$
\begin{aligned}
& m_{15,13}=e^{K_{4} x_{4}} \cdot \cos K_{4} x_{4}, \\
& m_{15,14}=e^{K_{4} x_{4}} \cdot \sin K_{4} x_{4}, \\
& m_{15,15}=e^{-K_{4} x_{4}} \cdot \cos K_{4} x_{4}, \\
& m_{15,16}=e^{-K_{4} x_{4}} \cdot \sin K_{4} x_{4},
\end{aligned}
$$




$$
\begin{aligned}
m_{15,17} & =-e^{K_{5} x_{4}} \cdot \cos K_{5} x_{4}, \\
m_{15,18} & =-e^{K_{5} x_{4}} \cdot \sin K_{5} x_{4}, \\
m_{15,19} & =-e^{-K_{5} x_{4}} \cdot \cos K_{5} x_{4}, \\
m_{15,20} & =-e^{-K_{5} x_{4}} \cdot \sin K_{5} x_{4}, \\
b_{15} & =y_{p 5}-y_{p 4} .
\end{aligned}
$$

Row 16.

$$
\begin{aligned}
& m_{16,13}=K_{4} e^{K_{4} x_{4}}\left(\cos K_{4} x_{4}-\sin K_{4} x_{4}\right), \\
& m_{16,14}=K_{4} e^{K_{4} x_{4}}\left(\cos K_{4} x_{4}+\sin K_{4} x_{4}\right), \\
& m_{16,15}=-K_{4} e^{-K_{4} x_{4}}\left(\cos K_{4} x_{4}+\sin K_{4} x_{4}\right), \\
& m_{16,16}=K_{4} e^{-K_{4} x_{4}}\left(\cos K_{4} x_{4}-\sin K_{4} x_{4}\right), \\
& m_{16,17}=-K_{5} e^{K_{5} x_{4}}\left(\cos K_{5} x_{4}-\sin K_{5} x_{4}\right), \\
& m_{16,18}=-K_{5} e^{K_{5} x_{4}}\left(\cos K_{5} x_{4}+\sin K_{5} x_{4}\right), \\
& m_{16,19}=K_{5} e^{-K_{5} x_{4}}\left(\cos K_{5} x_{4}+\sin K_{5} x_{4}\right), \\
& m_{16,20}=-K_{5} e^{-K_{5} x_{4}}\left(\cos K_{5} x_{4}-\sin K_{5} x_{4}\right) .
\end{aligned}
$$

Row 17.

$$
\begin{aligned}
& m_{17,13}=-2 K_{4}^{2} e^{K_{4} x_{4}} \sin K_{4} x_{4}, \\
& m_{17,14}=2 K_{4}^{2} e^{K_{4} x_{4}} \cos K_{4} x_{4}, \\
& m_{17,15}=2 K_{4}^{2} e^{-K_{4} x_{4}} \sin K_{4} x_{4}, \\
& m_{17,16}=-2 K_{4}^{2} e^{-K_{4} x_{4}} \cos K_{4} x_{4}, \\
& m_{17,17}=2 K_{5}^{2} e^{K_{5} x_{4}} \sin K_{5} x_{4}, \\
& m_{17,18}=-2 K_{5}^{2} e^{K_{5} x_{4}} \cos K_{5} x_{4}, \\
& m_{17,19}=-2 K_{5}^{2} e^{-K_{5} x_{4}} \sin K_{5} x_{4}, \\
& m_{17,20}=2 K_{5}^{2} e^{-K_{5} x_{4}} \cos K_{5} x_{4} .
\end{aligned}
$$

Row 18.

$$
\begin{aligned}
m_{18,13}= & -2 K_{t 4} K_{4}^{3} e^{K_{4} x_{4}}\left(\cos K_{4} x_{4}+\sin K_{4} x_{4}\right) \\
& -K_{e 3} e^{K_{4} x_{4}} \cos K_{4} x_{4}, \\
m_{18,14}= & 2 K_{t 4} K_{4}^{3} e^{K_{4} x_{4}}\left(\cos K_{4} x_{4}-\sin K_{4} x_{4}\right) \\
& -K_{e 3} e^{K_{4} x_{4}} \sin K_{4} x_{4}, \\
m_{18,15}= & 2 K_{t 4} K_{4}^{3} e^{-K_{4} x_{4}}\left(\cos K_{4} x_{4}-\sin K_{4} x_{4}\right) \\
& -K_{e 3} e^{-K_{4} x_{4}} \cos K_{4} x_{4}, \\
m_{18,16}= & 2 K_{t 4} K_{4}^{3} e^{-K_{4} x_{4}}\left(\cos K_{4} x_{4}+\sin K_{4} x_{4}\right) \\
& -K_{e 3} e^{-K_{4} x_{4}} \sin K_{4} x_{4},
\end{aligned}
$$

$$
\begin{aligned}
m_{18,17} & =2 K_{t 5} K_{5}^{3} e^{K_{5} x_{4}}\left(\cos K_{5} x_{4}+\sin K_{5} x_{4}\right), \\
m_{18,18} & =-2 K_{t 5} K_{5}^{3} e^{K_{5} x_{4}}\left(\cos K_{5} x_{4}-\sin K_{5} x_{4}\right), \\
m_{18,19} & =-2 K_{t 5} K_{5}^{3} e^{-K_{5} x_{4}}\left(\cos K_{5} x_{4}-\sin K_{5} x_{4}\right), \\
m_{18,20} & =-2 K_{t 5} K_{5}^{3} e^{-K_{5} x_{4}}\left(\cos K_{5} x_{4}+\sin K_{5} x_{4}\right), \\
b_{18} & =K_{e 3} y_{p 4} .
\end{aligned}
$$

Row 19.

$$
\begin{aligned}
& m_{19,17}=e^{K_{5} x_{5}} \cdot \cos K_{5} x_{5}, \\
& m_{19,18}=e^{K_{5} x_{5}} \cdot \sin K_{5} x_{5}, \\
& m_{19,19}=e^{-K_{5} x_{5}} \cdot \cos K_{5} x_{5}, \\
& m_{19,20}=e^{-K_{5} x_{5}} \cdot \sin K_{5} x_{5}, \\
& m_{19,21}=-e^{K_{6} x_{5}} \cdot \cos K_{6} x_{5}, \\
& m_{19,22}=-e^{K_{6} x_{5}} \cdot \sin K_{6} x_{5}, \\
& m_{19,23}=-e^{-K_{6} x_{5}} \cdot \cos K_{6} x_{5}, \\
& m_{19,24}=-e^{-K_{6} x_{5}} \cdot \sin K_{6} x_{5}, \\
& b_{19}=y_{p 6}-y_{p 5} .
\end{aligned}
$$

Row 20.

$$
\begin{aligned}
& m_{20,17}=K_{5} e^{K_{5} x_{5}}\left(\cos K_{5} x_{5}-\sin K_{5} x_{5}\right), \\
& m_{20,18}=K_{5} e^{K_{5} x_{5}}\left(\cos K_{5} x_{5}+\sin K_{5} x_{5}\right), \\
& m_{20,19}=-K_{5} e^{-K_{5} x_{5}}\left(\cos K_{5} x_{5}+\sin K_{5} x_{5}\right), \\
& m_{20,20}=K_{5} e^{-K_{5} x_{5}}\left(\cos K_{5} x_{5}-\sin K_{5} x_{5}\right), \\
& m_{20,21}=-K_{6} e^{K_{6} x_{5}}\left(\cos K_{6} x_{5}-\sin K_{6} x_{5}\right), \\
& m_{20,22}=-K_{6} e^{K_{6} x_{5}}\left(\cos K_{6} x_{5}+\sin K_{6} x_{5}\right), \\
& m_{20,23}=K_{6} e^{-K_{6} x_{5}}\left(\cos K_{6} x_{5}+\sin K_{6} x_{5}\right), \\
& m_{20,24}=-K_{6} e^{-K_{6} x_{5}}\left(\cos K_{6} x_{5}-\sin K_{6} x_{5}\right) .
\end{aligned}
$$

Row 21.

$$
\begin{aligned}
& m_{21,17}=-2 K_{5}^{2} e^{K_{5} x_{5}} \sin K_{5} x_{5}, \\
& m_{21,18}=2 K_{5}^{2} e^{K_{5} x_{5}} \cos K_{5} x_{5}, \\
& m_{21,19}=2 K_{5}^{2} e^{-K_{5} x_{5}} \sin K_{5} x_{5}, \\
& m_{21,20}=-2 K_{5}^{2} e^{-K_{5} x_{5}} \cos K_{5} x_{5}, \\
& m_{21,21}=2 K_{6}^{2} e^{K_{6} x_{5}} \sin K_{6} x_{5},
\end{aligned}
$$




$$
\begin{aligned}
& m_{21,22}=-2 K_{6}^{2} e^{K_{6} x_{5}} \cos K_{6} x_{5}, \\
& m_{21,23}=-2 K_{6}^{2} e^{-K_{6} x_{5}} \sin K_{6} x_{5}, \\
& m_{21,24}=2 K_{6}^{2} e^{-K_{6} x_{5}} \cos K_{6} x_{5} .
\end{aligned}
$$

Row 22

$$
\begin{aligned}
& m_{22,17}=-2 K_{5}^{3} e^{K_{5} x_{5}}\left(\cos K_{5} x_{5}+\sin K_{5} x_{5}\right), \\
& m_{22,18}=2 K_{5}^{3} e^{K_{5} x_{5}}\left(\cos K_{5} x_{5}-\sin K_{5} x_{5}\right), \\
& m_{22,19}=2 K_{5}^{3} e^{-K_{5} x_{5}}\left(\cos K_{5} x_{5}-\sin K_{5} x_{5}\right), \\
& m_{22,20}=2 K_{5}^{3} e^{-K_{5} x_{5}}\left(\cos K_{5} x_{5}+\sin K_{5} x_{5}\right), \\
& m_{22,21}=2 K_{6}^{3} e^{K_{6} x_{5}}\left(\cos K_{6} x_{5}+\sin K_{6} x_{5}\right), \\
& m_{22,22}=-2 K_{6}^{3} e^{K_{6} x_{5}}\left(\cos K_{6} x_{5}-\sin K_{6} x_{5}\right), \\
& m_{22,23}=-2 K_{6}^{3} e^{-K_{6} x_{5}}\left(\cos K_{6} x_{5}-\sin K_{6} x_{5}\right), \\
& m_{22,24}=-2 K_{6}^{3} e^{-K_{6} x_{5}}\left(\cos K_{6} x_{5}+\sin K_{6} x_{5}\right) .
\end{aligned}
$$

Row 23.

$$
\begin{aligned}
m_{23,21} & =e^{K_{6} x_{6}} \cdot \cos K_{6} x_{6}, \\
m_{23,22} & =e^{K_{6} x_{6}} \cdot \sin K_{6} x_{6}, \\
m_{23,23} & =e^{-K_{6} x_{6}} \cdot \cos K_{6} x_{6}, \\
m_{23,24} & =e^{-K_{6} x_{6}} \cdot \sin K_{6} x_{6}, \\
b_{23} & =-y_{p 6} .
\end{aligned}
$$

Row 24.

$$
\begin{aligned}
& m_{24,21}=e^{K_{6} x_{6}}\left(\cos K_{6} x_{6}-\sin K_{6} x_{6}\right), \\
& m_{24,22}=e^{K_{6} x_{6}}\left(\cos K_{6} x_{6}+\sin K_{6} x_{6}\right), \\
& m_{24,23}=-e^{-K_{6} x_{6}}\left(\cos K_{6} x_{6}+\sin K_{6} x_{6}\right), \\
& m_{24,24}=e^{-K_{6} x_{6}}\left(\cos K_{6} x_{6}-\sin K_{6} x_{6}\right) .
\end{aligned}
$$

\section{References}

[1] I. Rosal-Fernandez, "How costly is the maintenance of the coalmining jobs in Europe? The Spanish case 1989-1995," Energy Policy, vol. 28, no. 8, pp. 537-547, 2000.

[2] Ministry of Industry, Energy and Tourism. Institute for Restructuring of Coal Mining and Alternative Development of Mining Regions. Report of the national strategic coal reserve 2006-2012 and new model for comprehensive and sustainable development of mining regions, 2013, http://www.irmc.es/.

[3] RGNBSM, General Regulation of Basic Procedure of Mining Safety. Spain, Ministry of Industry and Energy, 2006, (Spanish).

[4] J. Gómez de las Heras, Provisions and design support in unions panel-gallery on pit-horizontal layers machined. Madrid, GeoMiner Technologic Institute of Spain, Ministry of Industry, Trade and Tourism, 1988, (Spanish).
[5] R. Lindsay Galloway, A History of Coal Mining in Great Britain, Augustus M. Kelley, New York, NY, USA, 1969.

[6] Energy Information Administration, Office of Coal, Nuclear, Electric and Alternate Fuels, Longwall Mining, U. S. Department of Energy, Washington, DC, USA, 1995.

[7] Medium-term coal market report 2012, OECD Publishing. IEA, 2012.

[8] Coal mining. World coal. World Coal Institute, 2009.

[9] P. Darling, SME Mining Engineering Handbook, Society for Mining, Metallurgy, and Exploration (SME), 3rd edition, 2011.

[10] A. A. Waddington and D. R. Kay, "Recent development in the incremental profile method of predicting subsidence, tilt and strain over a series of longwall Panels," in Proccedings of the International Conference on Geomechanics/Ground Control in Mining and Underground Construction, Wollongong, Australia, July 1998.

[11] A. García-Bello, J. Ordieres-Meré, and C. González-Nicieza, "Generalization of the influence function method in mining subsidence," International Journal of Surface Mining, Reclamation and Environment, vol. 10, no. 4, pp. 195-202, 1996.

[12] G. W. Mitchell, "Longwall mining," in Australasian Coal Mining Practice, R. J. Kininmonth and E. Y. Baafi, Eds., pp. 340-373, The Australasian Institute of Mining and Metallurgy, Melbourne, Australia, 2010.

[13] M. S. Venkata Ramayya and L. Sudhakar, "Selection of powered roof support for weak coal roof," Journal of Mines, Metals and Fuels, vol. 50, no. 4, pp. 114-117, 2002.

[14] R. Singh and T. N. Singh, "Investigation into the behaviour of a support system and roof strata during sublevel caving of a thick coal seam," Geotechnical and Geological Engineering, vol. 17, no. 1, pp. 21-35, 1999.

[15] J. Ju and J. Xu, "Structural characteristics of key strata and strata behaviour of a fully mechanized longwall face with $7.0 \mathrm{~m}$ height chocks," International Journal of Rock Mechanics and Mining Sciences, vol. 58, pp. 46-54, 2013.

[16] N. Bilim and I. Özkan, "Determination of the effect of roof pressure on coal hardness and excavation productivity: an example from a Çayırhan lignite mine, Ankara, Central Turkey," International Journal of Coal Geology, vol. 75, no. 2, pp. 113-118, 2008.

[17] C. González-Nicieza, A. Menéndez-Díaz, A. E. Álvarez-Vigil, and M. I. Álvarez-Fernández, "Analysis of support by hydraulic props in a longwall working," International Journal of Coal Geology, vol. 74, no. 1, pp. 67-92, 2008.

[18] R. Juárez-Ferreras, C. González-Nicieza, A. Menéndez-Díaz, A. E. Álvarez-Vigil, and M. I. Álvarez-Fernández, "Forensic analysis of hydraulic props in longwall workings," Engineering Failure Analysis, vol. 16, no. 7, pp. 2357-2370, 2009.

[19] R. Juárez-Ferreras, C. González-Nicieza, A. Menéndez-Díaz, A. E. Álvarez-Vigil, and M. I. Álvarez-Fernández, "Measurement and analysis of the roof pressure on hydraulic props in longwall," International Journal of Coal Geology, vol. 75, no. 1, pp. 49-62, 2008.

[20] S. P. Timoshenko and J. N. Goodier, Theory of Elasticity, McGraw- Hill, New York, NY, USA, 1970.

[21] V. I. Klishin and T. M. Tarasik, "Stand tests of hydraulic props in dynamic loads," Journal of Mining Science, vol. 37, no. 1, pp. 77-84, 2001. 


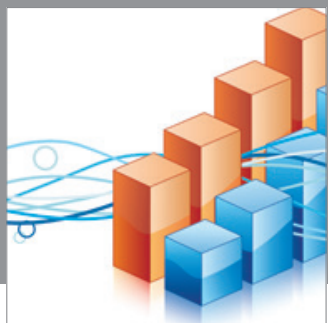

Advances in

Operations Research

mansans

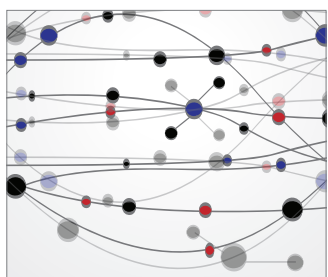

The Scientific World Journal
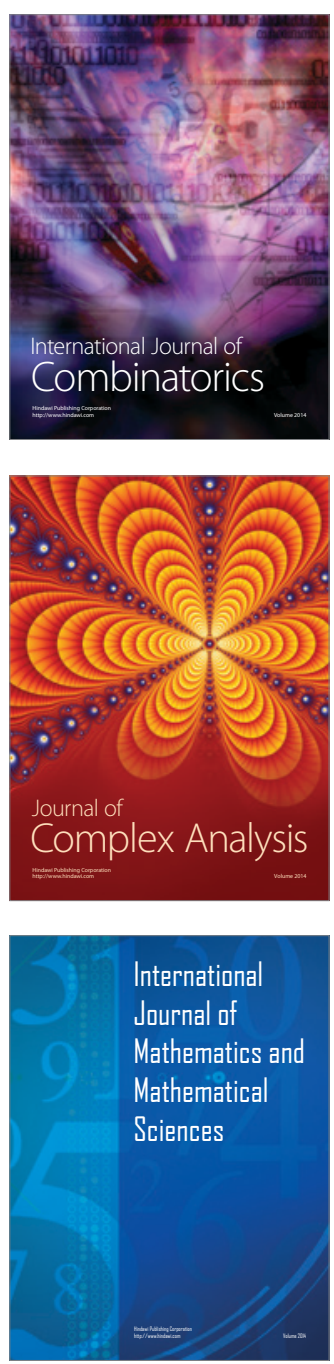
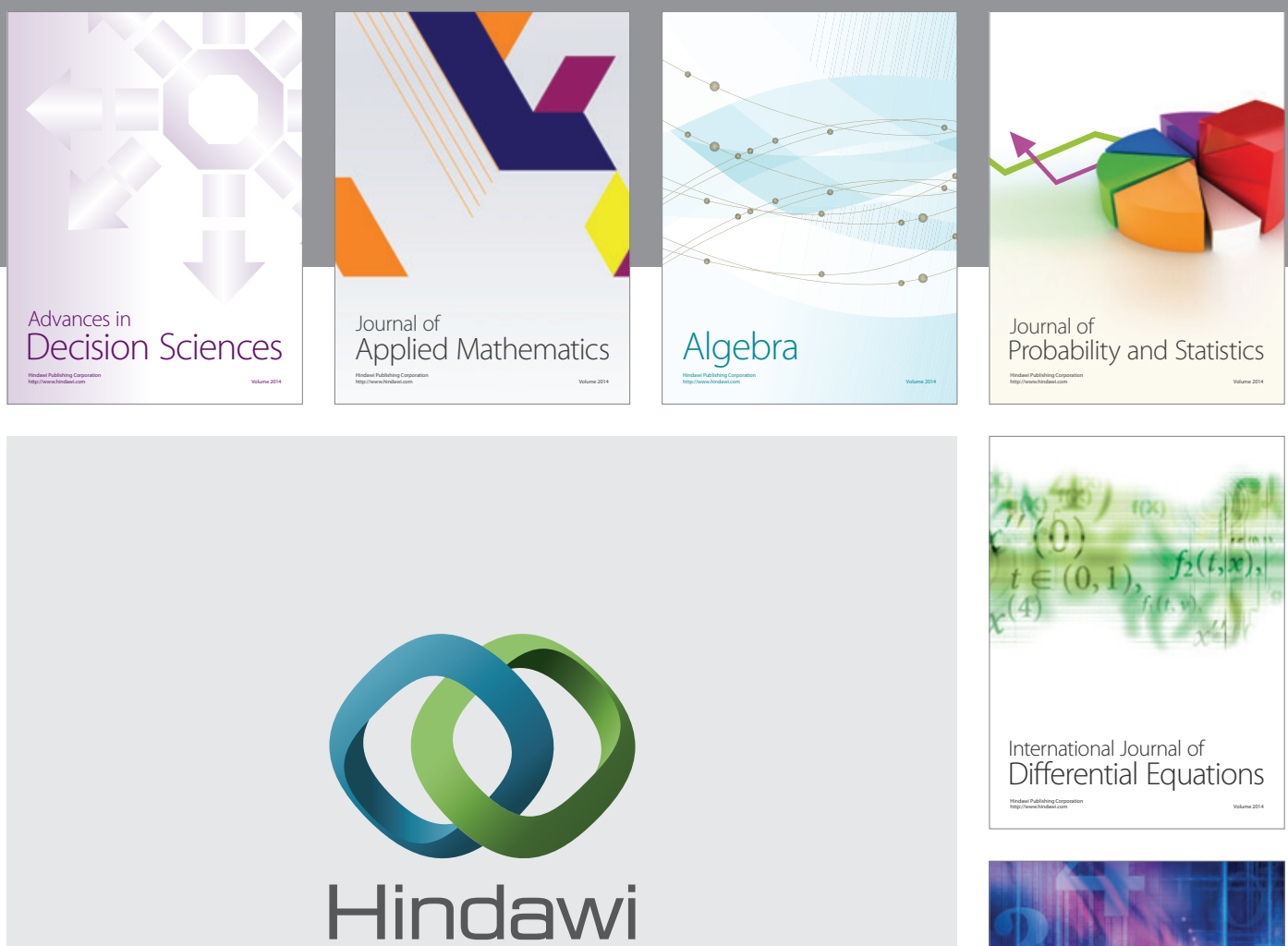

Submit your manuscripts at http://www.hindawi.com
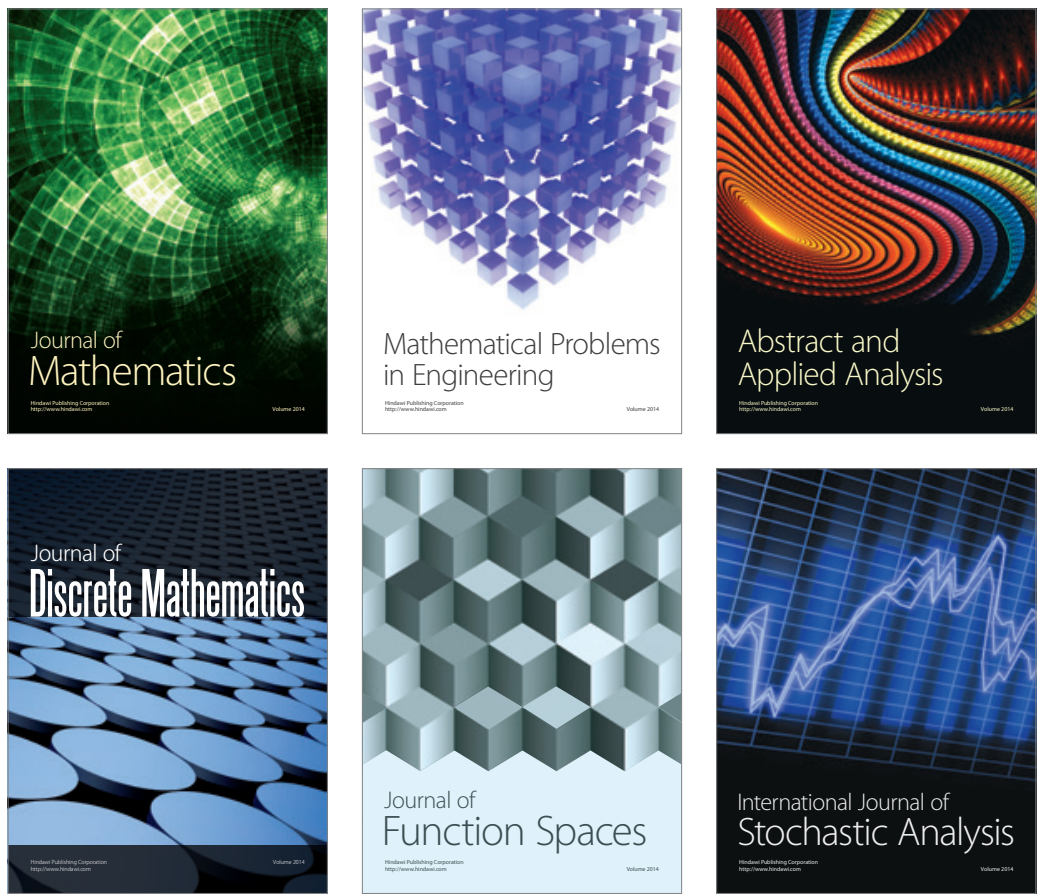

Journal of

Function Spaces

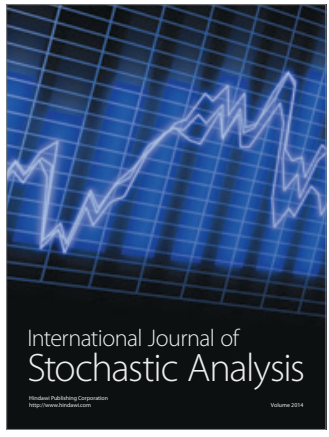

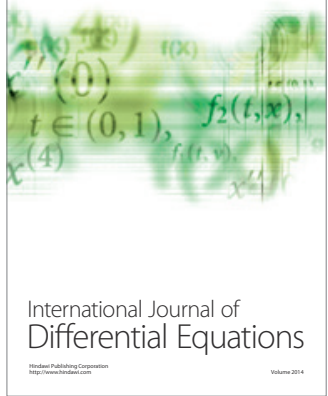
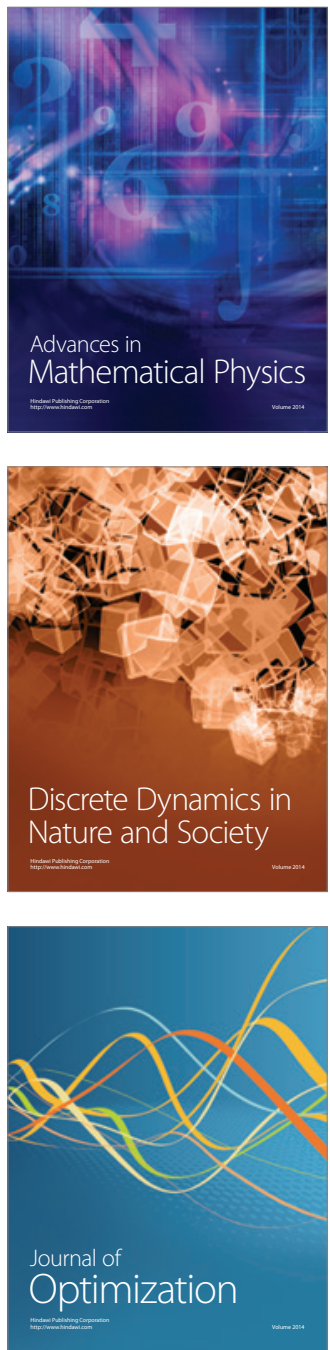